\title{
$\infty \sqrt{1}$ Stroke and \\ Role of endovascular embolisation for curative treatment of intracranial non- Galenic pial arteriovenous fistula
}

\author{
Hengwei Jin, ${ }^{1}$ Xiangyu Meng (10 , ${ }^{2}$ Jiale Quan, ${ }^{3}$ Yi Lu, ${ }^{2}$ Youxiang Li ${ }^{4}$
}

To cite: Jin H, Meng X, Quan J, et al. Role of endovascular embolisation for curative treatment of intracranial nonGalenic pial arteriovenous fistula. Stroke \& Vascular Neurology 2021;6: e000482. doi:10.1136/svn-2020-000482

$\mathrm{HJ}$ and XM contributed equally.

Received 3 July 2020 Revised 26 August 2020 Accepted 22 October 2020 Published Online First 9 December 2020

\section{Check for updates}

(C) Author(s) (or their employer(s)) 2021. Re-use permitted under CC BY-NC. No commercial re-use. See rights and permissions. Published by BMJ.

${ }^{1}$ Department of Interventional Neuroradiology, Beijing Tiantan Hospital, Beijing, China

${ }^{2}$ Interventional Neuroradiology department, Beijing

Neurosurgical Institute, Beijing, China

${ }^{3}$ Pediatric department, Dongming People's Hospital, Beijing, China

${ }^{4}$ Department of Interventional Neuroradiology, Beijing Neurosurgical Institute, Beijing, China

Correspondence to Dr Youxiang Li; liyouxiang@263.net

\section{ABSTRACT}

Background and purpose The safety and effectiveness of endovascular treatment for non-Galenic pial arteriovenous fistula (NGPAVF) is inadequately known. The aim of this study is to explore the role of endovascular embolisation for curative treatment of NGPAVF.

Materials and methods Patients with NGPAVF underwent endovascular treatment from January 2011 to November 2019 in our institution were retrospectively reviewed. Demographics, clinical information, treatment details and clinical outcomes were collected. Factors associated with clinical outcomes were statistically analysed.

Results Twenty patients were included, with a total of 22 (2 patients have 2 fistulas) lesions. A total of 25 procedures were performed and 5 patients underwent 2 procedures. Follow-up ranged from 3 to 84 months (mean=34.5 months). Thirteen (59.1\%) lesions in $12(60.0 \%)$ patients acquired immediate occlusion after initial treatment (immediately occluded group) and follow-up confirmed the complete obliteration. A total of 17 (77.3\%) lesions in 15 (75.0\%) patients were cured at last follow-up. The maximal diameter of feeding arteries $(p=0.04)$ and the maximal diameter of the varix $(p=0.01)$ in immediately occluded group was smaller than non-immediately occluded group. The number of feeding artery $(p=0.004)$ and the maximal diameter of the varix $(p<0.001)$ were much smaller in curative group than non-curative group. Seven patients suffered procedure-related complications. No patients had an increased Modified Rankin Scale (mRS) and all patients had favourable clinical outcome ( $m R S \geq 2$ ) at last follow-up. Conclusions Endovascular therapy plays an important role in curative treatment of NGPAVF. Patients with less feeding arteries and small varix may be easier to be cured by endovascular embolisation.

\section{INTRODUCTION}

Intracranial non-Galenic pial arteriovenous fistula (NGPAVF) is a type of arteriovenous malformation (AVM) consisting of a direct high-flow connection between pial artery and vein with the existence of a giant varix. ${ }^{1}$ The main difference between AVM and NGPAVF was the absence of nidus in patients with NGPAVF. The incidence of this malformation is lower than that of AVM. NGPAVFs account for about $1.6 \%-4.8 \%$ of AVM. ${ }^{2}$ They arise sporadically both as isolated phenomena and in congenital. There may be one or more feeding arteries, and unlike Galenic pial arteriovenous fistula which only involved the Galen vein enlargement and a direct connection between pial artery and Galen vein, NGPAVF can occur everywhere in the brain. ${ }^{3}$ The main treatment modalities of NGPAVF include surgical resection and endovascular embolisation. Due to its extremely low incidence, only sporadic cases have been reported. ${ }^{4-6}$ The safety and effectiveness of endovascular treatment for NGPAVF is inadequately known. To explore the role of endovascular embolisation for curative treatment of NGPAVF, we reviewed patients with NGPAVF who underwent endovascular embolisation at our institution.

\section{MATERIALS AND METHODS}

\section{Patient characteristics}

We retrospectively reviewed patients with NGPAVF treated with endovascular embolisation at our institution from 2011 to 2019. Patients' basic information, clinical information, angiography characteristics, treatment details and follow-up results were collected. The Galenic pial arteriovenous fistulas were all excluded from this study. The Modified Rankin Scale (mRS) was adopted to evaluate the neurofunctions of patients at last follow-up. All patients underwent imaging (Digital Subtraction Angiography (DSA)) follow-up. mRS $\leq 2$ was defined as favourable clinical outcome and $\mathrm{mRS} \geq 3$ was defined as unfavourable clinical outcome.

\section{Radiographic characteristics}

The location of NGPAVFs was confirmed by CT or MRI scan combined with DSA. Complete occlusion immediately after procedure was defined as the absence of the fistula and early vein drainage. Curative treatment was defined as complete occlusion after the last embolisation and no recurrence at the last follow-up. The diameter of the feeding artery was measured at the proximal of the fistula. If there were multiple supply arteries feeding into one lesion, the maximal value 
among all the obtained feeding arteries was used as the maximal diameter of the feeding artery. All the varices in each patient were measured from three different angles, and the maximal value was taken as the largest diameter of the intracranial varix.

\section{Statistical analysis}

Patients' characteristics were described with frequencies for categorical variables and mean SD for continuous variables. Categorical variables were compared using Fisher's exact test or the Pearson's $\chi^{2}$ test. Continuous variables were compared using Student's t-test. Univariate logistic analysis was done to assess factors that influenced the treatment result including immediate occlusion after initial embolisation and cure at last follow-up. Spearman's correlation analysis was adopted to compare the relationship between maximum diameter of feeding artery or varix and immediate occlusion. $\mathrm{P}<0.05$ was considered to be statistically significant. All statistical analyses were conducted using SPSS V.22.0 (Chicago, Illinois, USA).

\section{RESULTS}

\section{Clinical characteristics}

A total of 20 patients were involved, including 13 (65.0\%) males and $7(35.0 \%)$ females. The median age at presentation was 7.5 years (3-45 years). Initial presentations included intracranial haemorrhage $(n=4,20.0 \%)$, seizures $(n=4,20.0 \%)$, dizziness and headache $(n=6$, $30.0 \%)$, neurological deficits $(n=4,20.0 \%)$ and discovered by accident without any symptom $(n=2,10.0 \%)$. Four patients had a history of treatment at local hospitals, including two $(10.0 \%)$ endovascular embolisation, one $(5.0 \%)$ craniotomy and one ventriculoperitoneal shunt because of hydrocephalus. Two patients had concomitant congenital disease. One was tetralogy of Fallot and the other was hereditary haemorrhagic telangiectasia (HHT). Six patients had a history of head injury. In four patients, NGPAVF was found by CT/MR several hours after the injury. In one patient, CT scan was performed 4 days after injury when the patient had headache. In one patient, left temporal NGPAVF was found 6 months after injury when the patient had proptosis and decreased vision in the left eye. Clinical characteristics are listed in table 1.

\section{Angioarchitecture characteristics}

The angioarchitecture characteristics of patients are listed in table 2. There were 22 lesions in 20 patients. Two patients had multiple lesions (patients 11 and 17), which were located at different sites (figure 1). Nine (45.0\%) patients had fistulas with one feeding artery, eight $(40.0 \%)$ with two feeding arteries and three (15.0\%) with $\geq 3$ feeding arteries. Mean number of feeding artery was 1.75 (range from 1 to 4 ) and the mean maximal diameter of the feeding artery was $5.37 \pm 0.60 \mathrm{~mm}$. Seven $(35.0 \%)$ patients had deep venous drainage. A total of 33 varices were found, $11(55.0 \%)$ patients had one varix, 6 $(30.0 \%)$ patients had two varices and $3(15.0 \%)$ patients had $\geq$ three varices (figure 2 ). The mean diameter of the

\begin{tabular}{lc}
\hline \multicolumn{2}{l}{ Table 1 Characteristics of all the patients } \\
\hline Characteristics & Number (\%) \\
\hline Total number & $20(100)$ \\
Gender & $13(65.0)$ \\
\hline Male & $7(35.0)$ \\
\hline Female & \\
\hline Age & $3-35(7.5)$ \\
\hline Range (median, years old) & $13(65.0)$ \\
\hline$\leq 18$ & $7(35.0)$ \\
\hline >18 & $6(30.0)$ \\
\hline History of head injury & $2(10.0)$ \\
\hline Combined with other congenital disease & \\
\hline Presentations & $4(20.0)$ \\
\hline Haemorrhage & $4(20.0)$ \\
\hline Seizures & $6(30.0)$ \\
\hline Headache & $4(20.0)$ \\
\hline Neurological deficits & $2(10.0)$ \\
\hline No symptom & \\
\hline Preoperative mRS & $15(75.0)$ \\
\hline Grade 0 & $3(15.0)$ \\
\hline Grade 1 & $2(10.0)$ \\
\hline Grade 2 & \\
\hline
\end{tabular}

mRS, Modified Rankin Scale.

varix was $3.73 \pm 0.39 \mathrm{~cm}$. Among all the patients, one had an aneurysm located at feeding artery and was completely embolised.

\section{Treatment outcome}

A total of 20 patients with 22 lesions were treated by endovascular therapy. Multiple lesions were found in two patients which were anatomically distant and harbouring a separate draining vein for each fistula (patients 11 and 17). In patient 11, two lesions were embolised at separate sessions. Both lesions of patient 17 were occluded (figure 1) at the same session. In 13 patients $(65.0 \%)$, the fistula was immediately occluded after initial treatment, and follow-up showed no recurrence. In patient 13, lesion was not occluded immediately after initial embolisation, while spontaneously occluded at last follow-up. In all, 17 $(77.3 \%)$ lesions in $15(75.0 \%)$ patients were cured at last follow-up.

Five patients were not completely occluded at last follow-up (patients 11, 14, 6, 9 and 12, figure 3). The two lesions of patient 11 were embolised at different sessions and the patient suffered haemorrhage when embolising the second lesion at the second session. Patient 12 suffered transient blurred vision and patient 14 suffered nystagmus and limb weakness after procedure and completely recovered at last follow-up. The mRS of the three patients with complications were all 0 at last follow-up. Two of them (patient 11 and 14) received additional endovascular embolisation at local hospital and we 


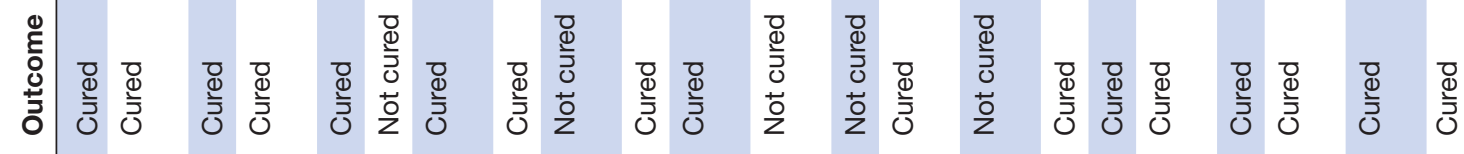

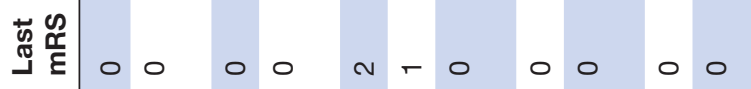

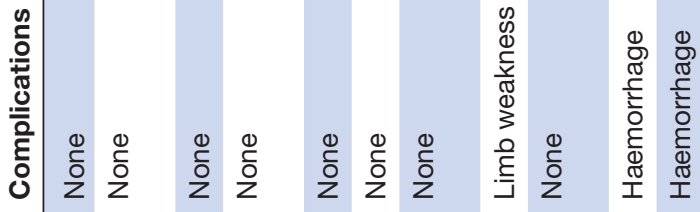

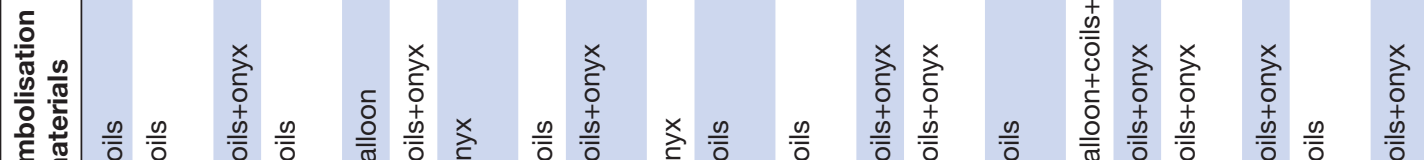

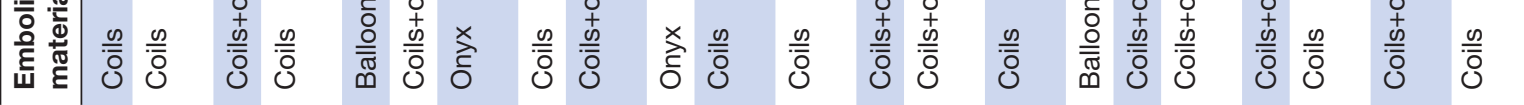

$\leftarrow \stackrel{9}{0}$

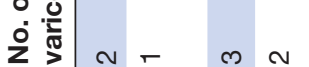

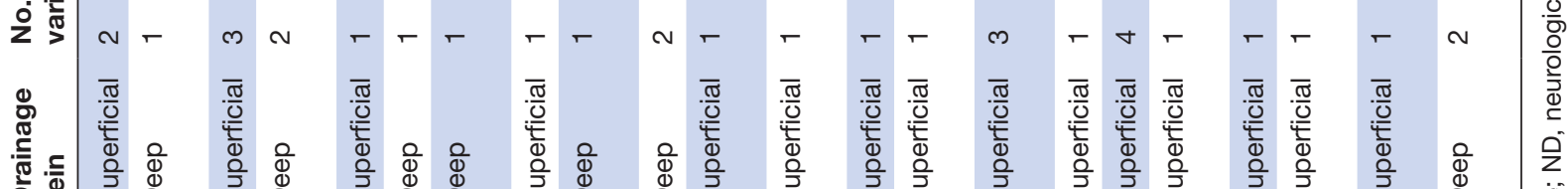

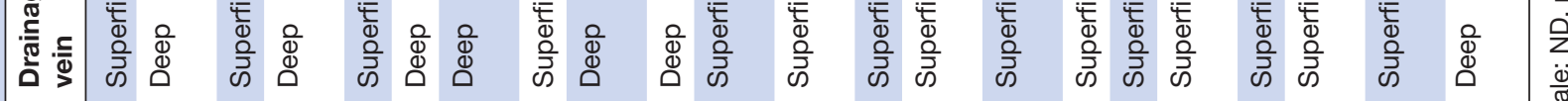

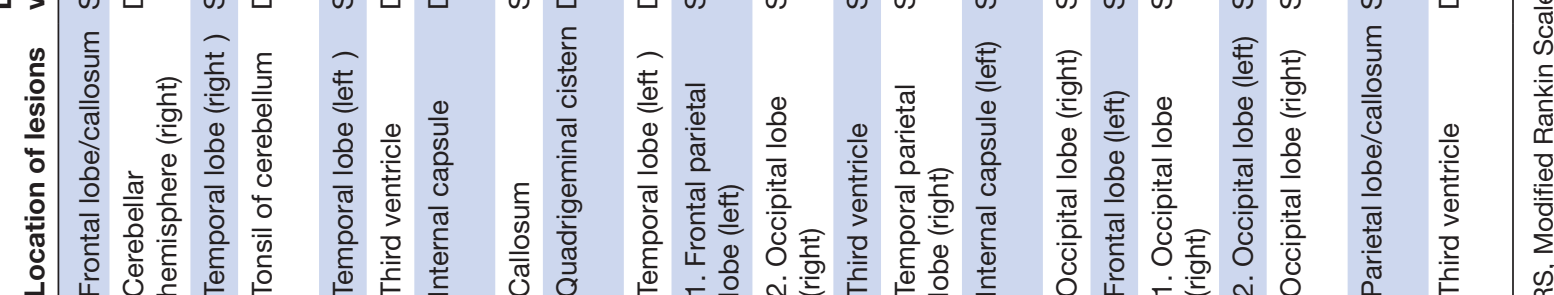

营

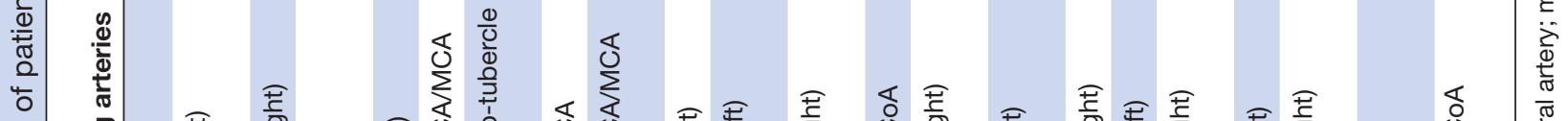

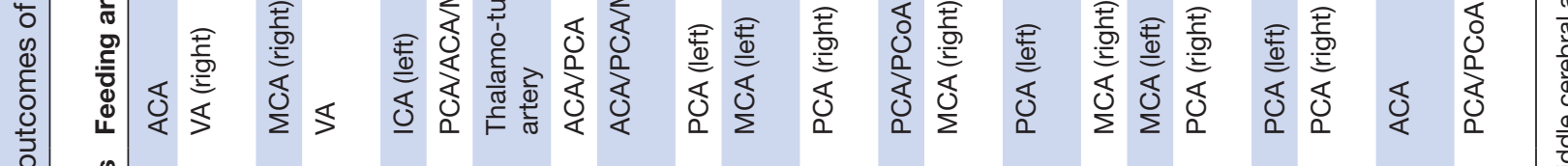

बत

竞

$\overline{\widetilde{\sigma}}$

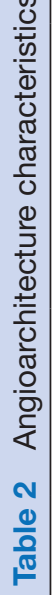

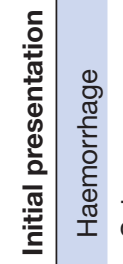

00

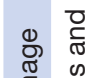

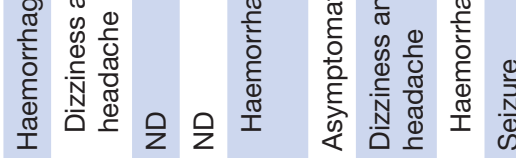

훙.

8

을.

N

స్心

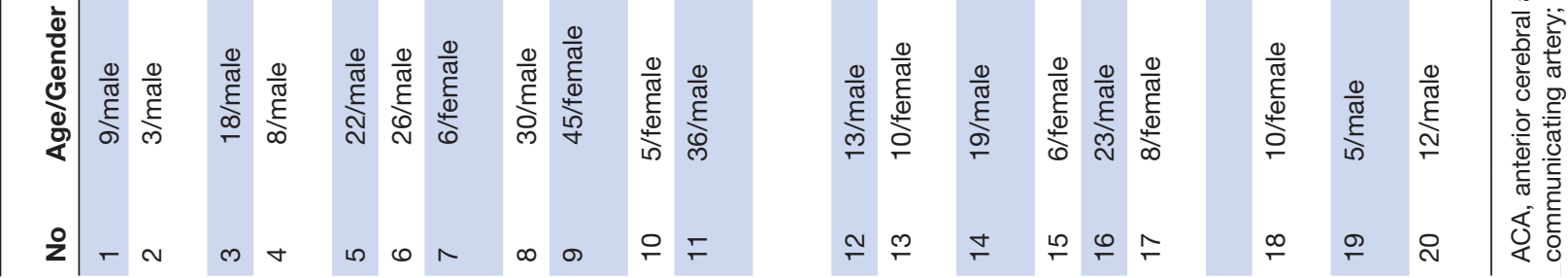




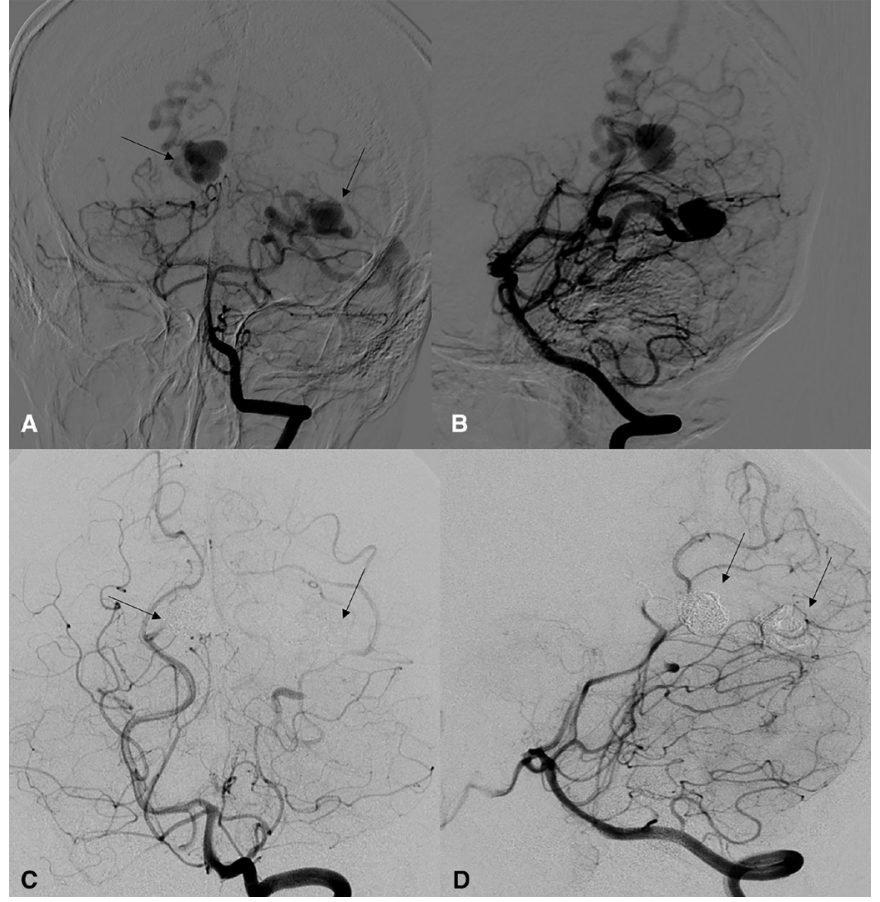

Figure 1 A girl aged 8 years (patient 17) presents with headache. Multiple lesions located at different sites. Frontal (A) and lateral (B) view of preoperative angiography. There are two dilated varices located at different sites (arrows). Frontal (C) and lateral (D) view of postoperative angiography. Both lesions are all completely embolised with a combination of onyx and coils.

were told by the patient that they were completely obliterated, but images were not available. The remaining three patients received no additional treatment up to last follow-up. The symptoms were well controlled, and no haemorrhage occurred.

Seven patients experienced procedure-related complications, two of them (patients 10 and 11) suffered intracranial haemorrhage after embolisation and totally recovered $(\mathrm{mRS}=0)$ at last follow-up. One patient (patient 16) experienced increased frequency of seizures after treatment and his symptoms were controlled by medication. Three patients experienced ischaemic neurological deficits (blurred vision in patient 12, nystagmus and limb weakness in patient 14 , left limb weakness in patient 8). They all completely recovered at last follow-up. Patient 15 suffered transient postoperative headache and totally recovered at discharge. Multivariate and univariate analyses showed no statistical significance in predicting complications. Two patients had a decreased mRS during follow-up. Pre-treatment and post-treatment mRS are all listed in table 2. All patients had favourable clinical outcome $(\mathrm{mRS} \leq 2)$ at last follow-up.

In terms of embolisation materials, nine (40.9\%) lesions were treated with coil, two $(9.1 \%)$ with onyx and one $(4.5 \%)$ with detachable balloon. Nine $(40.9 \%)$ lesions were treated with a combination of coils and onyx, one $(4.5 \%)$ with coils, balloon and onyx. The occlusion rate of patients embolised with coils and onyx was $44.4 \%$

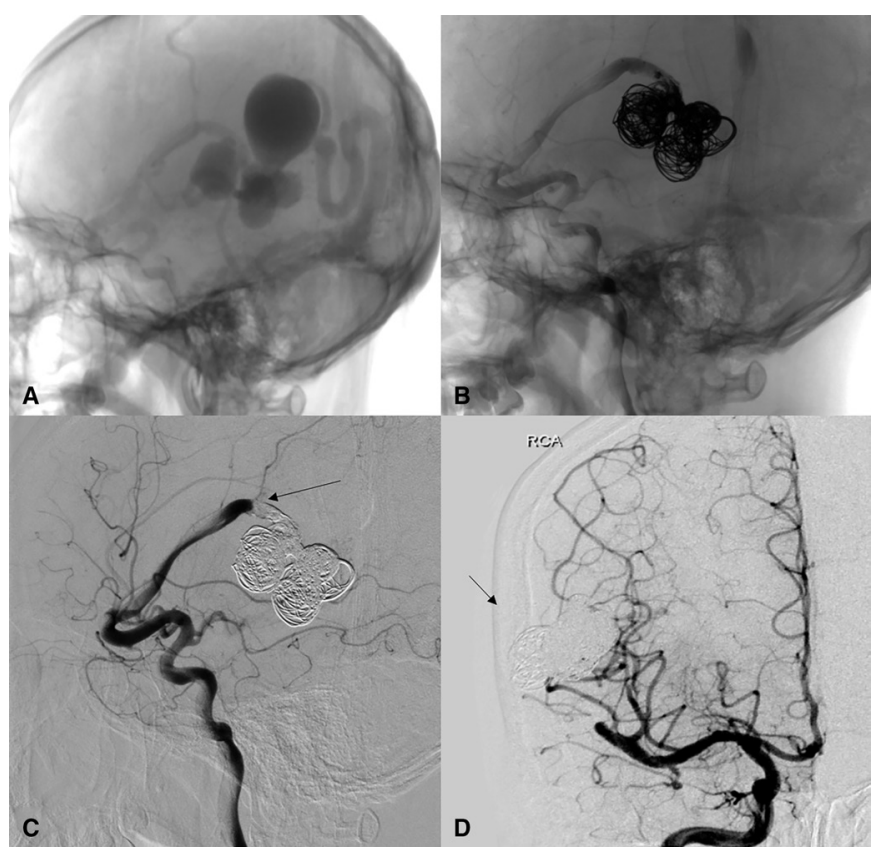

Figure 2 A boy aged 18 years (patient 3) presents with intracranial haemorrhage. Preoperative angiogram (A) shows multiple varices located in the temporoparietal lobe fed by R-MCA. Intraoperative angiogram (B) shows varices and feeding artery are embolised with onyx and coils. Lateral view (C) of postoperative angiogram shows the main feeding artery (arrow) is occluded at the proximal of the fistula. Frontal view (D) of postoperative angiogram shows the varices (arrow) are occluded.

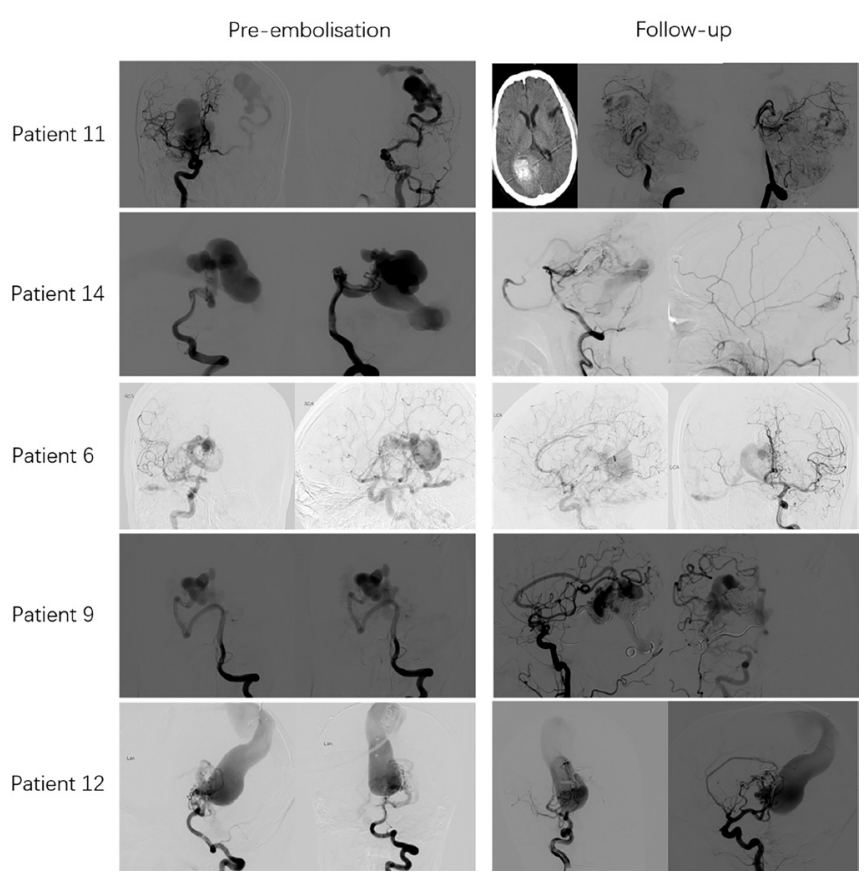

Figure 3 Pre-embolisation and follow-up angiogram of incomplete obliteration of non-Galenic pial arteriovenous fistula (NGPAVF) in five patients (patients 11, 14, 6, 9 and 12). The two lesions of patient 11 were embolised at different sessions and the patient suffered haemorrhage (CT) when embolising the second lesion at the second session. 
Table 3 Univariate and multivariate analyses of predictors for immediate occlusion after initial embolisation

\begin{tabular}{|c|c|c|c|c|c|c|}
\hline \multirow[b]{2}{*}{ Factors } & \multicolumn{3}{|c|}{ Univariate } & \multicolumn{3}{|c|}{ Multivariate } \\
\hline & OR & $95 \% \mathrm{Cl}$ & $P$ value & OR & $95 \% \mathrm{Cl}$ & $P$ value \\
\hline No. of feeding arteries & - & 0.12 to 1.35 & 0.09 & - & - & NA \\
\hline Deep drainage & 0.46 & 0.08 to 2.58 & 0.65 & - & - & NA \\
\hline Maximum diameter of the varix & - & 0.89 to 4.50 & 0.006 & 1.59 & 0.82 to 3.06 & 0.11 \\
\hline
\end{tabular}

NA, not available.

immediately after the initial embolisation, while that of patients embolised with other materials (onyx, coils, balloon alone or a combination of coils, balloon and onyx) was $69.2 \%$. Statistical analysis showed no significance between two groups $(\mathrm{p}=0.38)$.

Univariate analysis showed that the maximal diameter of feeding arteries in patients who were immediately occluded after initial embolisation (immediately occluded group) was smaller than patients who were not occluded immediately after initial embolisation (non-immediately occluded group) $(4.35 \pm 0.74 \mathrm{~mm}$ vs $6.83 \pm 0.81 \mathrm{~mm}$, $\mathrm{p}=0.04)$. The maximal diameter of the varix in immediately occluded group was also significantly smaller than that of non-immediately occluded group $(3.49 \pm 0.44 \mathrm{~cm}$ vs $6.18 \pm 0.83 \mathrm{~cm}, \mathrm{p}=0.01$ ) (table 3 ). Spearman's correlation analysis found a correlation between the maximum diameter of the varix and the effect of immediate embolisation $(\mathrm{p}=0.004, \mathrm{r}=0.583$, figure 4$)$.

A total of $17(77.3 \%)$ lesions were cured at the last follow-up. Statistical analysis showed the number of feeding arteries and the maximal diameter of the varix were much smaller in curative group than non-curative

Spearman's correlation analysis about maximum diameter of feeding artery

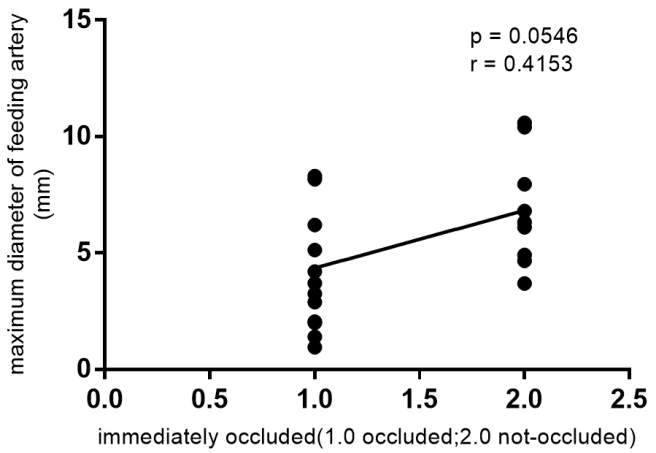

Spearman's correlation analysis about maximum diameter of varix

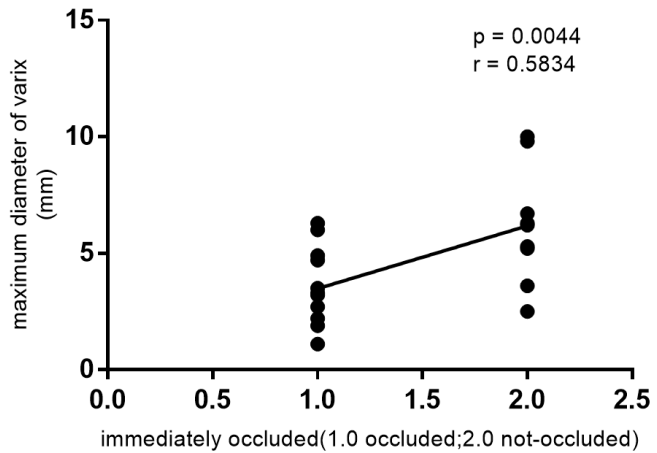

Spearman's correlation analysis about number of feeding arteries

Spearman's correlation analysis about maximum diameter of varix
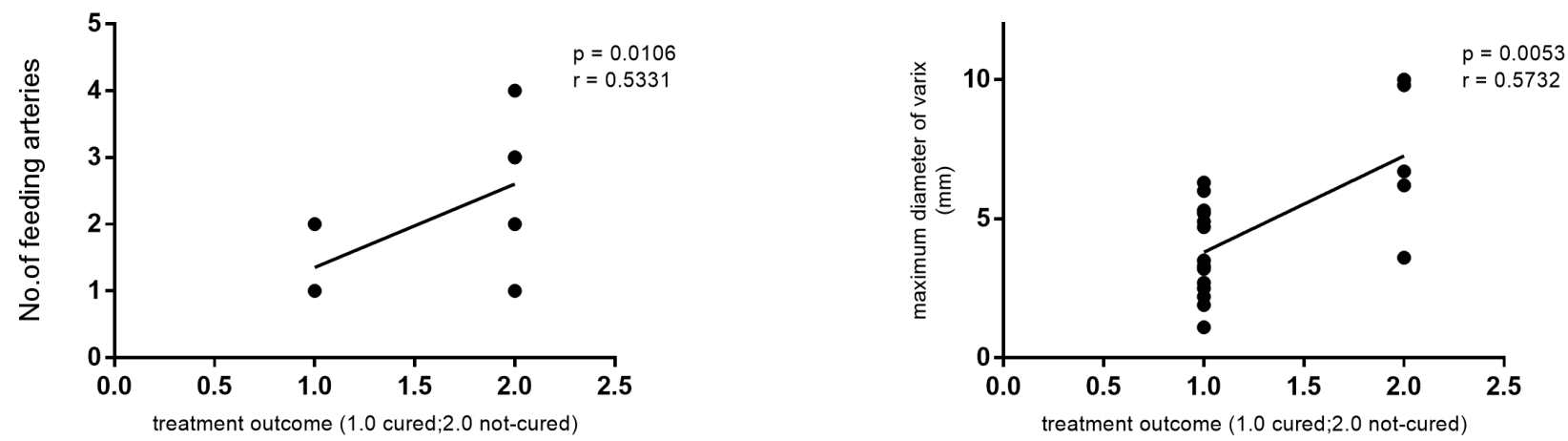

Figure 4 Spearman's correlation analysis of factors affecting immediate occlusion and final cure. The two graphs above show that maximum diameter of varix has significant correlation with immediate occlusion $(p=0.004, r=0.583)$. The two graphs below show that both number of feeding arteries and maximum diameter of varix have significant correlation with curative treatment (number of feeding arteries, $p=0.011, r=0.533$; maximum diameter of varix, $p=0.005, r=0.573$ ). 
Table 4 Univariate and multivariate analyses of predictors for curative treatment by endovascular therapy

\begin{tabular}{|c|c|c|c|c|c|c|}
\hline \multirow[b]{2}{*}{ Factors } & \multicolumn{3}{|c|}{ Univariate } & \multicolumn{3}{|c|}{ Multivariate } \\
\hline & OR & $95 \% \mathrm{Cl}$ & P value & OR & $95 \% \mathrm{Cl}$ & $P$ value \\
\hline No. of feeding arteries & - & 0.40 to 1.85 & 0.004 & - & NA & 0.996 \\
\hline Deep drainage & 0.63 & 0.10 to 4.46 & 0.99 & - & - & NA \\
\hline Maximum diameter of the varix & - & 1.69 to 5.59 & $<0.001$ & - & NA & 0.998 \\
\hline
\end{tabular}

NA, not available.

group (mean number of feeding artery $1.47 \pm 0.12$ vs $2.60 \pm 0.51, \mathrm{p}=0.004$; mean maximal diameter of the varix $3.62 \pm 0.38 \mathrm{~cm}$ vs $7.26 \pm 1.20 \mathrm{~cm}, \mathrm{p}<0.001$ ) (table 4 ). Spearman's correlation analysis showed that these two factors had significant correlation with curative treatment (number of feeding arteries, $\mathrm{p}=0.011, \mathrm{r}=0.533$; maximum diameter of the varix, $\mathrm{p}=0.005, \mathrm{r}=0.573$ ) (figure 4 ).

\section{DISCUSSION}

In 1966, McCormick ${ }^{7}$ proposed a classification of vascular malformations in which the NGPAVF was separately categorised. Attentions have been gradually paid to NGPAVF which is different from brain AVM. ${ }^{46^{8-11}}$ In early years, the attempts to treat NGPAVF with interventional neuroradiology were often unsuccessful. Inability to fully visualise NGPAVF angioarchitecture was the main reason leading to incomplete embolisation. This problem has been solved with technological innovation and the development of embolic materials. Pretreatment selective and super-selective angiography has made it possible to observe the accurate angioarchitectural characteristics, which is essential for complete embolisation of the lesion. ${ }^{12}$ The current study focused on curative treatment of endovascular treatment for NGPAVF. It is a rare vascular disorder of the brain and only a few cases have been reported. ${ }^{13-16}$ Endovascular embolisation was an effective and conventional treatment modality. ${ }^{10} 17$ In a study of 10 paediatric patients with NGPAVF, Requejo et $a l^{15}$ reported that eight $(80 \%)$ patients were treated with embolisation. In this retrospective study, a total of 17 $(77.3 \%)$ lesions in $15(75.0 \%)$ patients were cured at last follow-up by endovascular embolisation, with no patient having an increased mRS. Two patients had relieved symptoms and had a decreased mRS. All patients had a favourable clinical outcome at last follow-up. This study indicates that endovascular therapy is safe and effective for curative treatment of NGPAVF.

NDPAVF is a challenging entity for craniotomy or stereotactic surgery (SRS) since it is usually located deeply with dilated arteries and veins, as well as very high blood flow, which poses great risk for craniotomy and low possibility of obliteration for SRS. Endovascular embolisation is a promising therapy for curative treatment. In this cohort, all the patients received endovascular therapy with the goal of total obliteration, while due to high blood flow, inaccessible tortuous feeding arteries and the uncontrollability of embolisation materials, five patients did not have total obliteration. In 16 patients, endovascular was the first-line therapy at our institution. Four patients had a history of treatment at local hospitals, including two $(10.0 \%)$ endovascular embolisation, one $(5.0 \%)$ craniotomy and one ventriculoperitoneal shunt because of hydrocephalus. Our multidisciplinary group have discussed the feasibility, the risks and benefits of every patient before treatment. Treatment of NGPAVF is not devoid of important complications, including haemorrhage/oedema from congestion of the surrounding brain which all of a sudden receives normal blood supply; seizures from the previous mechanism as well as from irritation form thrombus within the large varices, and the risk of potential extension of the thrombosis into distal normal parenchymal veins. Specific patient/angiographic features used to determine the management include the age, symptoms, location of the lesion, accessibility of feeding arteries, the high blood flow and uncontrollability of embolisation materials and so on.

NGPAVFs are proposed to be mainly congenital and often diagnosed at young age. Generally, congenital NGPAVFs may accompany other diseases such as HHT or congestive heart failure. ${ }^{18}$ In a series of 41 paediatric patients with NGPAVF, Weon et $a l^{19}$ found that $11 / 41$ (26.8\%) patients had HHT and identified a family history. The rate of patients combining with a congenital disease in our series was $10 \%$. Two patients had concomitant congenital diseases. One had tetralogy of Fallot and the other had HHT. Another aetiology of NGPAVF was traumatic and iatrogenic, especially when the blood vessels of the cerebral cortex were damaged and communications formed between the vessels. ${ }^{20}$ Several cases of traumatic and iatrogenic NGPAVF have been reported. ${ }^{52122}$ In our series, six patients had a history of head injury. In four patients, NGPAVF was found by CT/MR immediately (several hours) after the injury. The NGPAVF in these patients was not considered to be traumatic because there was not enough time for the formation of the varices. In one patient, CT scan was performed 4 days after very mild head injury when the patient had headache. The NGPAVF was suspiciously traumatic. In one patient, left temporal NGPAVF was found 6 months after mild injury when the patient had proptosis and decreased vision in the left eye. The NGPAVF was drained by ophthalmic vein. This lesion was very likely to be traumatic. While in the two patients, 
they did not have any imaging data before or immediately after injury, which caused difficulty in confirmation.

In this study, we initially did some explorations in terms of factors related to curative treatment. The cure rate of patients embolised with coils and onyx is $44.4 \%$ immediately after the initial embolisation, while that of patients embolised with other materials (onyx, coils, balloon alone or a combination of coils, balloon and onyx) is $69.2 \%$. Yu et $a l^{20}$ also found that embolisation with coils or onyx (with or without balloon assistance) may lead to a better therapeutic effect. Presumably both agents were used because fistulas were larger or more complex, thus this is a biased result. It requires more cases to prove. Univariate analysis showed that lesions that completely occluded immediately after initial embolisation had a smaller maximal diameter of the feeding artery and a smaller maximal diameter of the varix compared with patients without immediate occlusion. In correlation analysis, maximum diameter of varix showed a significant correlation with immediate occlusion. The number of feeding artery and the maximal diameter of the varix were much smaller in curative patients than non-curative patients. They both showed correlation with curative treatment. Less number of feeding arteries and smaller diameter of the varix may be potential factors affecting clinical result of endovascular therapy.

\section{CONCLUSIONS}

Endovascular therapy plays an important role in curative treatment of NGPAVF. Patients with less feeding arteries and small varix may be easier to be cured by endovascular embolisation.

Contributors All authors contributed to the study conception and design. This study was designed by YoL. Material preparation, data collection and analysis were performed by JQ and YiL. The first draft of the manuscript was written by $\mathrm{HJ}$ and $\mathrm{XM}$. All authors commented on previous versions of the manuscript. All authors read and approved the final manuscript.

Funding This study was supported by the National Key Research and Development Program of China(Grant No. 2017YFB1304400)

Competing interests None declared.

Patient consent for publication Not required.

Ethics approval This study is in accordance with the ethical standards of the institutional and/or national research committee and with the 1975 Helsinki Declaration and its later amendments or comparable ethical standards. Informed consent was obtained from all individual participants included in the study. Provenance and peer review Not commissioned; externally peer reviewed. Data availability statement Data are available on reasonable request.

Open access This is an open access article distributed in accordance with the Creative Commons Attribution Non Commercial (CC BY-NC 4.0) license, which permits others to distribute, remix, adapt, build upon this work non-commercially, and license their derivative works on different terms, provided the original work is properly cited, appropriate credit is given, any changes made indicated, and the use is non-commercial. See: http://creativecommons.org/licenses/by-nc/4.0/.

ORCID iD

Xiangyu Meng http://orcid.org/0000-0002-7703-1177

\section{REFERENCES}

1 Lasjaunias P, Manelfe C, Chiu M. Angiographic architecture of intracranial vascular malformations and fistulas--pretherapeutic aspects. Neurosurg Rev 1986;9:253-63.

2 Upchurch K, Feng L, Duckwiler GR, et al. Nongalenic arteriovenous fistulas: history of treatment and technology. Neurosurg Focus 2006;20:1-8

3 Agarwal H, Sebastian LJD, Gaikwad SB, et al. Vein of Galen aneurysmal malformation-clinical and angiographic spectrum with management perspective: an institutional experience. J Neurointerv Surg 2017;9:159-64.

4 Maejima R, Ohshima T, Miyachi S, et al. Neonatal intracranial pial arteriovenous fistula treated with endovascular embolization: a case report. World Neurosurg 2018;118:261-4.

5 Nomura S, Ishikawa O, Tanaka K, et al. Pial arteriovenous fistula caused by trauma: a case report. Neurol Med Chir 2015;55:856-8.

6 Okazaki T, Sakamoto S, Ishii D, et al. A pial arteriovenous fistula in infancy as the presenting manifestation of hereditary hemorrhagic telangiectasia. World Neurosurg 2019;122:322-5.

7 McCormick WF. The pathology of vascular ("arteriovenous") malformations. J Neurosurg 1966;24:807-16.

8 Pedicelli A, lacobucci M, Frassanito P, et al. Prenatal diagnosis and multimodal neonatal treatment of a rare pial arteriovenous fistula: case report and review of the literature. World Neurosurg 2017;104:1050.e13-1050.e18.

9 Lin T-C, Chang T-W, Wu Y-M, et al. De novo formation of pial arteriovenous fistulas: systematic review of acquired lesions and their clinical differences compared with primary lesions. World Neurosurg 2019;128:e276-82.

10 Terada A, Komiyama M, Ishiguro T, et al. Nationwide survey of pediatric intracranial arteriovenous shunts in Japan: Japanese pediatric arteriovenous shunts study (JPAS). J Neurosurg Pediatr 2018;22:550-8.

11 Goel A, Jain S, Shah A, et al. Pial arteriovenous fistula: a brief review and report of 14 surgically treated cases. World Neurosurg 2018:110:e873-81.

12 Lawdahl RB, Routh WD, Vitek JJ, et al. Chronic arteriovenous fistulas masquerading as arteriovenous malformations: diagnostic considerations and therapeutic implications. Radiology 1989;170:1011-5.

13 Paramasivam S, Toma N, Niimi Y, et al. Development, clinical presentation and endovascular management of congenital intracranial pial arteriovenous fistulas. J Neurointerv Surg 2013:5:184-90.

14 Hoh BL, Putman CM, Budzik RF, et al. Surgical and endovascular flow disconnection of intracranial pial single-channel arteriovenous fistulae. Neurosurgery 2001;49:1351-64.

15 Requejo F, Jaimovich R, Marelli J, et al. Intracranial pial fistulas in pediatric population. clinical features and treatment modalities. Childs Nerv Syst 2015;31:1509-14.

16 Hetts SW, Keenan K, Fullerton HJ, et al. Pediatric intracranial nongalenic pial arteriovenous fistulas: clinical features, angioarchitecture, and outcomes. AJNR Am J Neuroradiol 2012;33:1710-9.

17 Youn SW, Han MH, Kwon BJ, et al. Coil-based endovascular treatment of single-hole cerebral arteriovenous fistulae: experiences in 11 patients. World Neurosurg 2010;73:2-10.

18 Sugiyama T, Nakayama N, Terasaka S, et al. Giant calcified thrombosed varices secondary to a pial arteriovenous fistula associated with hereditary hemorrhagic telangiectasia. Neurol Med Chir 2012;52:506-9.

19 Weon YC, Yoshida Y, Sachet M, et al. Supratentorial cerebral arteriovenous fistulas (AVFs) in children: review of 41 cases with 63 non choroidal single-hole AVFs. Acta Neurochir 2005;147:17-31.

20 Yu J, Shi L, Lv X, et al. Intracranial non-galenic pial arteriovenous fistula: a review of the literature. Interv Neuroradiol 2016;22:557-68.

21 Schuette AJ, Blackburn SL, Barrow DL, et al. Pial arteriovenous fistula resulting from ventriculostomy. World Neurosurg 2012;77:785.e1-785.e2.

22 Nishiyama Y, Kanemaru K, Yoshioka H, et al. Intracranial pial arteriovenous fistula caused by dural tenting: case report. Neurol Med Chir 2014;54:242-4. 